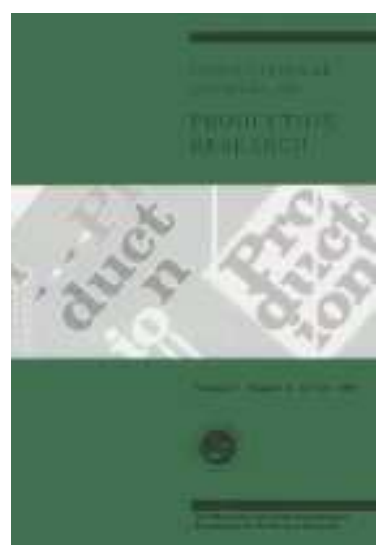

\title{
INVENTORY MANAGEMENT PRACTICES AND THEIR IMPACT ON PERCEIVED PLANNING PERFORMANCE
}

\begin{tabular}{|r|l|}
\hline Journal: & International Journal of Production Research \\
\hline Manuscript ID: & TPRS-2006-IJPR-0059.R1 \\
\hline Manuscript Type: & Original Manuscript \\
\hline Author: & 14-May-2006 \\
\hline Complete List of Authors: & $\begin{array}{l}\text { Jonsson, Patrik; Chalmers University of Technology, Division of } \\
\text { logistics and transportation } \\
\text { Mattsson, Stig-Arne; Lund University, Department of industrial } \\
\text { management and logistics }\end{array}$ \\
\hline Keywords: & $\begin{array}{l}\text { MRP, INVENTORY CONTROL, MATERIALS MANAGEMENT, } \\
\text { PERFORMANCE ANALYSIS }\end{array}$ \\
\hline Keywords (user): & \\
\hline &
\end{tabular}

\section{s ScholarONE" \\ Manuscript Central}




\section{Inventory management practices and their implications on perceived planning performance}

\author{
Patrik Jonsson* \\ Division of Logistics and Transportation \\ Chalmers University of Technology \\ 41282 Gothenburg, Sweden \\ E-mail: patrik.jonsson@chalmers.se \\ Ph: +46317721336 \\ Fax: +46317721337
}

\author{
Stig-Arne Mattsson \\ Department of Industrial Management and \\ Logistics \\ Lund University \\ Box 118, 22100 Lund, Sweden \\ E-mail: stig-arne.mattsson@tlog.lth.se
}

\section{*Corresponding author}




\title{
Inventory management practices and their implications on
}

\author{
perceived planning performance
}

\begin{abstract}
This paper focuses on the use of material planning methods to control material flow to inventories of purchased items. The first sub-objective is to evaluate the perceived planning performance of material planning methods used to control material flows in different inventory types in manufacturing and distribution companies. The second sub-objective is to evaluate the difference in perceived planning performance depending on the way planning parameters are determined and the methods used. Five material planning methods are studied: the re-order point method, the fixed order interval method, run-out time planning, kanban and MRP. Analysis is based on survey data from 153 manufacturing and 53 distribution companies. Findings conclude that the use of material planning methods differs depending on where along the material flow they are applied, whether the inventory is located in a manufacturing or in distribution operations and between companies of various sizes. The modes of applying a material planning method affect its perceived performance. In particular, the way of determining and the review frequency of safety stocks and lead times have great importance for the planning performance of MRP methods, while the determination and review of order points, review frequencies and runout times were important for re-order point methods.
\end{abstract}


Keywords: inventory management, planning environment, planning parameters, materials requirements planning, re-order point, performance

\section{INTRODUCTION}

This study deals with inventory management practices at the tactical planning level, also known as material planning. It concerns balancing supply and demand - i.e. the initiation, control and monitoring of manufacturing and purchasing orders in order to maintain an uninterrupted material flow and value-adding activity in manufacturing and warehouses.

There are a number of material planning methods, which control material flows in different ways, for example the re-order point, fixed order interval, run-out time, kanban and material requirements planning (MRP) methods (e.g. Seetharama et al., 1995, Vollmann et al., 2005). These methods may be more or less appropriate depending on the type of inventory they control, i.e. if they are used for controlling the replenishment stocks of purchased items used in manufacturing, controlling manufacturing or the replenishment of finished goods stocks in distribution operations (Rabinovish and Evers, 2002). Material planning methods can also be considered to perform differently well depending on the environment where they are used (Krajewski et al., 1987, Berry and Hill, 1992, Jonsson and Mattsson, 2003).

Material planning performance is partly a result of whether appropriate methods are employed and whether they are used correctly. For example, a method could be expected to perform better if lead times, safety stocks, re-order points, batch sizes etc. represent reality rather than not. To do this, the parameters may need to be analytically determined (safety stocks calculated from determined service levels etc.) rather than experience-based. 
However, studies show that this is not always the case: "Surprisingly, many companies use outdated, simplistic methods for allocating safety stocks, and they do not ever know it" (Sandvig, 1998). Wilkinson (1996) writes that "in the last few years, we have worked for over 30 clients, in excess of $90 \%$ of these did not set mathematically based safety stock levels". Jonsson and Mattsson (2006) conducted a longitudinal study of the use of material planning methods in manufacturing companies between 1993 and 2005. They concluded that a common way of determining parameters such as order quantities and safety stocks is by general judgment and experience. They also concluded that the proportion of companies with replanning capability in their Enterprise Resource Planning (ERP) systems has increased, but only a minor portion of the companies use automatic replanning.

The parameters should also be updated periodically in order to adjust dynamically to the changing environment. Furthermore, the planning frequency may have an important performance impact, especially in environments characterised of uncertain demand (e.g. Lee, 2002) where daily rather than weekly planning would probably result in more appropriate plans. The Jonsson and Mattsson (2006) study also showed that parameters used in the material planning methods were reviewed rather infrequently, typically once a year or less in over half of the companies. For re-order point methods, there was a general trend towards less frequent reviewing.

Consequently, planning performance may be affected by the type of inventory and the planning environment where it is used and how parameters are determined in the first place, how often they are reviewed or the planning frequency. However, there has been little empirical analysis of the performance impacts of the planning environment and the way material planning methods are used or how planning parameters are determined. 
The first objective of this paper is to evaluate the perceived planning performance of material planning methods used to control material flows in different inventory types in manufacturing and distribution companies. The second objective is to evaluate the perceived planning performance depending on the way planning parameters are determined and the methods used. The analysis is based on survey data.

\section{FRAME OF REFERENCE}

\subsection{Material Planning Methods for Inventory Management}

The two essential questions to address in material planning are "When to order/deliver?" and "How much to order?" - i.e. one time-related and one quantity-related. There are a number of material planning methods, which answer these two questions in different ways and can be categorised as working with dependent or independent demand. Materials requirements planning (MRP) is the best known and most widely used method for dependent demand. Re-order point methods (ROP), fixed order interval method (FOI), runout time planning (ROT) and kanban are common methods for independent demand (see e.g. Vollmann et al., 2005). The run-out time planning method (e.g. Seetharama et al., 1995) is synonymous with the cover time planning method (e.g. Segerstedt, 2006). These five methods are included in this study.

Material planning methods have a number of different replenishment mechanisms (reorder points, replenishment intervals, run-out times, number of kanbans and the MRP calculation). However, they also include several common planning parameters, for example safety stocks, lead times and order quantities. 


\subsection{Inventory Types and Perceived Material Planning Performance}

Only a few studies focus on the adoption patterns of material planning methods in different types of inventories. Newman and Sridharan (1992) studied the use of re-order point methods, material requirements planning, kanban and OPT in US manufacturing companies: $56 \%$ used MRP, $22 \%$ used re-order point methods, and $8 \%$ used kanban. In the study by Cerveny and Scott (1989) in six different industries, 60\% were MRP users. Osteryoung et al. (1986) concluded that a majority of firms used re-order point methods for controlling finished goods inventories compared to work in process and raw materials. This is logical, since the items controlled in the finished goods inventory have independent demand and cannot be derived by exploding and off-setting the demand through the bill-ofmaterials as done in the MRP method. However, the distribution requirements planning (DRP) and time-phased order point methods are MRP related alternatives to the re-order point related methods in such an environment. An earlier study by Reuter (1978) concluded that $85 \%$ of the examined companies used re-order point methods for placing orders with suppliers. The study did not separate purchase of finished products and purchase of items to be used as input to manufacturing. This may explain the heavy use of the re-order point method. It is, however, also logical to believe that the re-order point method is suitable for replenishment of inventories of purchased input items to manufacturing, especially for those that are standard items used for making several different products and therefore have quite even demand and picking frequency in the inventory. There are, however, studies indicating a somewhat different usage pattern in various inventory types. Rabinovich and Evers (2002) showed that MRP was used to a significantly greater extent than re-order 
point methods in controlling material flows in raw material inventories, work in progress and finished goods inventories. The differences in adoption patterns between the studies may to some extent be explained by when they were conducted. Jonsson and Mattsson (2006), for example, conducted a longitudinal study of the use of material planning methods in 1993, 1999 and 2005. They showed that MRP has strengthened its position as the most important material planning method and that the re-order point method decreased in importance between 1993 and 1999. The re-order point method is still the secondly most used method in industry. The study also showed that kanban has increased in use during the last decade.

The performance of the material planning method can be estimated in different ways. Firstly, it should constitute a good basis for achieving high operational performances, in terms of costs, tied-up capital and customer service. Secondly, it should be user friendly, i.e. easy to understand and use and efficient to operate. Operational performances could be expected to be lower if a method is used in an inappropriate environment (e.g. Krajewski et al., 1987, Berry and Hill, 1992). Jonsson and Mattsson (2003) explained how material planning methods performed in four types of manufacturing environments. MRP performed well in processes making complex customer products, but kanban did not. In processes configuring products to order, all material planning methods were suitable but MRP had the best fit. In batch production of standardised products, the re-order point methods had the best fit together with MRP and in repetitive mass production all methods performed well, however, kanban had the best fit. It was also identified that batch production of standardised products had significantly more satisfied material planning users compared to 
the other environments, thus, indicating that the material planning difficulties vary between environments.

It is also reasonable to assume that planning methods are more or less suitable and perform differently depending on whether they control raw material stocks, work in process or finished goods inventories (Rabinovich and Evers, 2002). Methods based on dependent demand (e.g. MRP) should have their greatest benefits for control of inventories in manufacturing and for controlling inventories of purchased items to be included in manufactured products. Methods based on independent demand (e.g. re-order point methods) should, on the other hand, be most important and perform best for controlling inventories of finished products and purchased items with low value and even demand. None of the "traditional" material planning methods make capacity considerations. However, there exist advanced planning and scheduling (APS) methods that conduct concurrent priority and capacity planning. The use of APS methods is still low in industry. No identified study has analysed the extent of APS use or how the APS related methodology is used and its perceived performance output. This methodology is not included in this study.

\subsection{Modes of Application and Perceived Material Planning Performance}

The performance of a material planning method can also be expected to differ depending on the quality of the planning parameters, i.e. to what extent the parameters are correct representations of reality (Sheu and Wacker, 2001). This may be a result of how the parameters are determined in the first place or how the planning method is used, i.e. how parameters are reviewed, and the modification and planning frequency of the orders. 
Determining order quantities is essentially an issue of balancing ordering costs and inventory carrying costs. Various categories of methods to accomplish such a balance can be identified, for example dynamic and fixed quantity models (e.g. Huang, 2000). Consequently, the approaches to determining the order quantity have a number of different characteristics that may influence user friendliness and operational performance. Enns (1999), for instance, showed the impact of various fixed order quantities on utilisation, work in process and meeting due dates. The results emphasised the importance of selecting proper batch sizes in MRP. Another study, by Wemmerlöv and Whybark (1984), showed that dynamic lot-sizing models resulted in higher overall performances compared to other models.

The optimum size of the order quantity is influenced by the current requirements. This means that in order to maintain as optimal order quantities as possible they must be reviewed periodically. How often this should be is an issue of balancing the cost of reviewing them with the benefits of maintaining them closer to the optimum. Experiencebased quantities are normally more time consuming and costly to review than calculationbased quantities. However, calculation-based quantities are more dependent on the quality of the basic data in order to produce reliable measures.

To protect the material flow from disruptions due to uncertainties in demand and supply, various safety mechanisms can be applied in all of the examined material planning methods. The uncertainty in supply and demand can basically be managed in two ways: by adding quantity buffers (i.e. using safety stock) or by adding time buffers (i.e. using safety time). Whybark and Williams (1976) used simulation studies to conclude that there are strong preferences for using safety lead times in MRP methods where demand or supply 
timing uncertainty exists, and using safety stocks where there is uncertainty in either the demand or supply quantity. Similar studies and findings relating to MRP methods (Molinder, 1997) and fixed order interval methods (Benton, 1991) have been carried out.

In most companies safety stocks are determined based on experience or by adding a fixed percentage to the lead-time demand (Jonsson and Mattsson, 2006). Of these approaches the experience-based approach cannot be updated automatically and is therefore more costly to review. Sandvig (1998), for example, states that surprisingly many companies use outdated and simplistic methods for allocating safety stocks.

Accurate lead times are very important in all material planning methods. This is for instance the case when calculating re-order points in re-order point methods, comparing run-out times with replenishment lead times in run-out time planning, and when off-setting start dates in material requirements planning. Lead times can be based on experience, calculations in the ERP system or monitored actual time. Zijm and Buitenhek (1996) discussed the problem with fixed lead times in MRP methods and compared it with workload-dependent lead times which resulted in significantly higher performance. Experience-based lead times have the same drawbacks as experience-based order quantities and safety stocks.

The modes of determining order quantities, safety mechanisms and lead times affect the possibility of obtaining accurate and appropriate measures. The frequency of reviewing the parameters also affects the dynamics of the methods and thereby the operational performance of the material planning (e.g. May, 1999). The review frequency is especially important in situations of varying demand and supply (Zhau and Lee, 1993). The planning frequency and ability of the method to automatically re-plan orders may result in more up- 
dated parameters and thus having the same impact on operational planning performance. However, frequent adjustments could also have an augmented effect, often referred to as system nervousness. One way of decreasing the nervousness would be to work with longer planning periods and by freezing time fences (Tang and Grubbström, 2002). Longer planning horizons may actually worsen MRP performance in a situation of uncertain demand but improve its performance in a deterministic case (Zhao and Lee, 1993). In addition to these general modes of applying methods, there are also method-specific modes - for example determination of order points, review periods, run-out times and number of kanbans.

\subsection{The Study Design}

The study is designed and analysis conducted in two steps, according to the objectives. To achieve high planning performance the material planning methods need to be used in appropriate planning environments. Here, we separate three different planning environments based on the type of inventory the method controls. The first type concerns inventory of purchased items to be used in manufacturing operations. The second concerns inventory of manufactured semi-finished goods and the third concerns inventory of purchased finished products, i.e. inventories in distribution operations or spare parts. We also separate the method use in small and large firms. In accordance with the previous discussion, some differences in use and perceived planning performance is expected for the respective methods in the different inventory types. This is the first part of the analysis (See Figure 1). 
To achieve high planning performance, the planning parameters used in the respective method also have to reflect the conditions in the planning environment. This can be accomplished by estimating them based on general judgement and experience. Setting parameters based on general judgment and experience means, however, that the parameters become very loosely connected to existing environmental conditions. By using analytical methods when determining the planning parameters, such relationships can be more exactly and accurately established. For example, the re-order point can more properly reflect the current lead time and demand if it is determined as the sum of the demand during lead time plus a safety stock rather than using a fixed number. Correspondingly, the safety stock can reflect the current variation in demand and determined service levels if it is analytically calculated rather than assessed as a fixed value.

As a result of frequent changes in the planning environment in most industries, planning parameters must also be reviewed and updated for the methods to work correctly. This concerns for instance changes in interest rates, ordering costs, demand, variation in demand and lead times. The need to review and update the parameters regularly is a concern irrespective of whether the parameters are manually estimated or analytically calculated by the ERP system. Frequent parameter updating can, however, be more easily accomplished by analytical methods. If, for example, the re-order point is determined as the demand during lead time plus a safety stock rather than a fixed number, the economic order quantity or other calculation method is used when determining order quantities, safety stock calculations are applied based on determined service levels and lead times are based on calculations in the ERP system, the parameters can automatically be updated when the environment changes. 
Another important concern in achieving high planning performance is planning frequency. More frequent planning results in more updated plans, which in most situations should lead to more accurate plans and thus higher planning performance. Less frequent material planning means planning with longer intervals, which means longer lead times from a planning perspective. This also contributes to increased uncertainty.

Manually modifying planned orders may have a positive performance impact because it could result in the changed order becoming more accurate. However, changes will result in alterations to other planned orders which may lead to lower performance. A manual change may also negatively affect perceptions of user friendliness.

In ERP systems supporting MRP it is often possible to generate re-planning suggestions and to automatically re-plan orders. Automatic re-planning overrules the planner, which could result in low performance, but is on the other hand more cost efficient than manual re-planning.

In accordance with the above discussion, the second part of the analysis relates to the level of analytically determining parameters and the review frequency, planning frequency, order modification and automatic re-planning ability when using the methods (Figure 1) and their perceived performance impact. Planning performance is measured as the "user friendliness" and "operational performance". The performance impact is analysed with statistical significance tests for the independent demand-oriented methods (re-order point, fixed order interval and run-out time methods) as a group and for the dependent demandoriented MRP method. Descriptive data is also presented for the re-order point, fixed order interval, run-out time and kanban methods, separately, but the samples are too small to conduct statistical significance tests. The independent demand method group will hereafter 
be denoted re-order point methods, as the methods (are) in several respects are variants of the traditional re-order point method.

Insert Figure 1 here

\section{METHODOLOGY}

\subsection{Selection and Data Collection}

Data collection was made by a web-based survey. E-mails about participation in the survey were sent to 573 member companies of the Swedish Production and Inventory Management Society (PLAN), an affiliate of APICS. Of these 573, 153 companies responded, which is a response rate of $31 \%$. We expected most PLAN companies to be in manufacturing and thus to use material planning methods for controlling stocks of purchased and manufacturing items. In order to include companies using material planning methods in distribution operations, the survey was also sent to logistics managers at all Swedish wholesaling companies with more than 20 employees. Addresses were provided by the Swedish postal service: 469 surveys were sent out and 53 useable responses were received, a response rate of $11 \%$. The questionnaire was quite long and some of the respondents from the wholesaling company selection were probably not inventory management experts, which may explain the relatively low response rates. About half of the respondents were from mechanical engineering companies and more than half were large companies (Table 1). 
Manufacturing companies with a turnover below SEK 100 million (equivalent to about 12 million Euro) or with less than 50 employees were defined as small. Those with a turnover between SEK 100 million and SEK 300 million and with more than 50 employees were considered medium-sized companies.

\section{Insert Table 1 here}

Generally speaking, PLAN members are distributed across manufacturing industries according to the average for Swedish manufacturing (i.e. with about half of the companies in the mechanical engineering sector). A reason for sending the questionnaire to PLAN members was that they were likely to have an interest in manufacturing planning and be familiar with the terminology used in the survey. Membership of PLAN is personal. Therefore, we did not expect the studied companies to be more advanced users of planning methods compared to the average for Swedish manufacturing, only that the respondents were more aware of the manufacturing planning and control area compared to the average. For the wholesaling companies, the situation is different. In this case, the survey was addressed to logistics managers. Several different material planning situations and applications could exist in one company, but we have included only one response per company in this analysis. Respondents were requested to answer only those sections they were familiar with and to pass the questionnaire to those in the company most qualified to 
answer particular sections. Therefore, it should be safe to assume that the responses were valid.

\subsection{The Survey Instrument}

There are four types of measures in this study. The first measures the use of the respective material planning method. The second measures the planning environment, here operationalised as inventory type. The third measures the mode of application of a specific planning method, and the fourth measures the perceived performance of the planning methods used. The classifications used and criteria measured follow the general manufacturing planning and control definitions (e.g. Vollmann et al., 2005).

In evaluating the use of planning methods, respondents were given four alternatives: (1) the method is not used, (2) the method is used as a complement, (3) the method is used as a main method, (4) don't know. Respondents marking alternatives 2 or 3 were coded as users. "Main method" was defined as the method used for the majority of items.

Here, the planning environment concerns the type of inventory that the method controlled. The respondents were given three alternatives: 1) control of inventories of purchased items to be used in manufacturing operations, 2) control of manufactured semifinished goods , 3) control of inventories of finished goods or spare parts in distribution operations.

The modes of application of the studied methods were measured in terms of the following: choice of lot-sizing methods, ways of considering uncertainties, level of analytical determination of re-order points, level of analytical determination of safety stocks and safety times, level of analytical determination of lead times, reviewing 
frequency of order quantities, reviewing frequency of safety stocks and safety times, reviewing frequency of lead times, and planning frequencies. Some additional planning variables were included for run-out time planning and kanban (see Table 2). Answers were coded "1" or "2", in accordance with Table 2. For MRP and re-order point methods, four indexes were formed, two for analytical parameter determination and two for parameter review frequency. Table 2 shows the definitions of the variables and indexes used for the re-order point methods and the MRP method.

\section{Insert Table 2 here}

Two variables and questions were used to measure the perceived planning performance: (1) User friendliness ("How easy is the method to understand and use, and how time consuming is it?"), and (2) Operational performance ("How well does the control of inventories and material flows match your expectations, in terms of achieving low tied-up capital, high customer service and few shortages?"). The answers were measured on sevenpoint scales, where "1" represented "poor"/"not at all", "4" satisfactory, and "7" "very well". Previous studies have used the perceived overall performance of manufacturing (Safizadeh et al., 1996), the inventory turnover rate (Rabinovich et al., 2003) and inventory days on hand in different inventories (Safizadeh and Ritzman, 1997) as measures for materials management performance. To validate our two measures of perceived planning performance we have included two measures that are in line with those tested and used in 
previous studies. The first is about the perceived overall inventory turnover rate in relation to the competitors in the industry (measured on a 7 point scale ranging from much lower to much higher) and the second about the perceived overall delivery service performance to customer in relation to the competitors in the industry (measured on a 7 point scale ranging from much worse to much better). These validity tests are explained in the next section.

\subsection{Reliability and Validity}

To increase the reliability and validity of the questionnaire, it was pre-tested and a number of questions were adjusted before finally sending out. Most respondents were PLAN members. This should ensure familiarity with planning methods.

The industry and size of the respondents closely matched the demographics of Swedish manufacturing firms in general (Olhager and Seldin, 2004). To increase the response rate and to identify the reasons for non-responses, potential respondents received a reminder by phone. Addresse(e)s were also requested to reply even if they did not intend to complete the questionnaire. Four main reasons were given for not answering the questionnaire, with a total of 111 non-reasonses. Fifty-four (49\%) stated that their company had no production or inventories and was therefore not relevant for the study; 27 (24\%) did not have sufficient knowledge to answer accurately; 23 (21\%) did not have enough time or did not wish to answer the questionnaire; and 7 (6\%) no longer worked for the company. The population of manufacturing companies could thus be adjusted to 533, which gives an adjusted response rate of $29 \%$. If $49 \%$ of all companies were irrelevant for study, then the response rate would be $55 \%$. The responding adjusted distribution company population is 455 and the adjusted response rates $12 \%$ and $22 \%$ respectively. Chi-square tests did not reveal any significant 
difference between respondents and non-respondents regarding company size or industry in any of the surveys. It should therefore be possible to generalise the findings for most manufacturing industries.

A four-page file with definitions and descriptions of the methods for material planning was attached to the surveys. The aim was to ensure that the measures were valid and that the respondents had the same definitions of planning methods, which further improved the understanding and validity of the study.

The criterion-related (predictive) validity of the subjective measure of perceived performance was tested by assessing the relationship between scores on the predictor scale and measures of the perceived overall inventory turnover rate in relation to the competitors in the industry (measured on a 7 point scale ranging from much lower to much higher) and the perceived overall delivery service performance to customer in relation to the competitors in the industry (measured on a 7 point scale ranging from much worse to much better). Table 3 shows the bivariate correlations between the measures. For MRP there are significant correlations between the perceived operational performance and both the inventory turnover rate and delivery service. The correlation between the perceived user friendliness and the delivery service is also significant. For the re-order point method there are significant correlation between both the perceived operational performance and user friendliness and the inventory turnover rate. However, the correlations with the delivery service are not significant. The correlations with the inventory turnover rate are expected to be higher than with the delivery service because the methods directly affects the inventory levels but only indirectly the delivery service. For the fixed order interval, run-out time planning and kanban methods the only significant correlation existed between the 
operational performance and delivery service for kanban. The levels of significance are lower for these methods, mainly because of lower number of respondents. The correlations between the perceived operational performance and perceived user friendliness are significant $(\mathrm{p}<0.01)$ for all methods. This is inline with the expectations that the user friendliness is positively affected by the operational performance. The correlation coefficient for the correlation between the two overall measures (inventory turnover rate and delivery service) was 0.154 , which was significant on the $\mathrm{p}<0.05$ level. These tests validate the appropriateness of using the perceived operational performance as a performance measure, especially for the MRP and re-order point methods.

\section{Insert Table 3 here}

\subsection{Statistical Tests}

The level of measurement of the questions differed between nominal, ordinal and interval scales. Therefore, various statistical methods were applied to analyse the data. The selection of the methods followed the guidelines of for example Siegel and Castellan (1988) and Hair et al. (1998). For scales of nominal and ordinal type, statistical analysis was carried out using chi-square tests for goodness of fit. For scales of interval type, ANOVA tests were used. 


\section{FINDINGS}

The analysis is conducted in two stages, according to the stated objectives. First, we study the use of methods to control the material flow in manufacturing companies' inventories of purchased and manufactured items and distribution operations' inventories and compare the perceived planning performance in different inventory types. Second, we compare the modes of application of the methods between firms with low and high perceived planning performance. Here, statistical significance tests are only conducted for the MRP and reorder point methods, because too few respondents using the other methods, as discussed in the methodology chapter.

\subsection{Material Planning Methods in Different Inventory Types and Company Sizes}

Table 4 shows the use of the five studied material planning methods to control the material flow to inventories of purchased and manufactured items in manufacturing companies and inventories in distribution companies. Re-order point and MRP methods are the significantly most common methods of controlling the material flow of purchased items. MRP is significantly most common in inventories of manufactured items compared to all other methods, and re-order point methods is significantly more common in inventories in distribution operations compared to all other methods. At first sight, it may be somewhat surprising that MRP is used in distribution operations because the method is not designed for controlling independent demand items. However, those saying they use MRP in distribution operations may use time-phased order point or distribution requirements planning, two variants of MRP. Kanban and run-out time planning are used in all inventory types, while the fixed order interval method is not used to any great extent in manufacturing 
companies. A reason for using re-order point related methods for controlling inventories of purchased items can be explained by the fact that there is a great extent of low value items and companies choose to control them with simpler replenishment methods than MRP.

\section{Insert Table 4 here}

Table 5 shows the number and percentages of main method users. The usage pattern is the same as for the general usage described in Table 4. MRP is significantly the most important main method of controlling material flows in inventories of purchased and manufactured items in manufacturing companies, while re-order point methods are most important in distribution operations.

\section{Insert Table 5 here}

Tables 6 and 7 show the perceived planning performance in different inventory types. No significant difference was identified between inventory types for the respective methods. This is surprising since the methods should be more or less suitable in the various inventory types and manufacturing environments. 
We also analysed the usage and general planning performance of each inventory management method in companies of various sizes and for companies in general, without considering inventory types or company sizes. When comparing companies of various sizes the significant difference with highest $\mathrm{p}$-value existed for the general use of the fixed order interval method with higher usage among small and medium sized companies and for main method usage of the re-order point method with more users among small and medium sized companies. The different usage of MRP between small/medium sized and large sized companies was significant on the $\mathrm{p}<0.11$ level with higher usage among large companies (Table 8). This is expected, since the method to a larger extent relies on ERP support compared to the other methods. The perceived planning performance did not, for any method, differ significantly between companies of various sizes (Table 9). The only significant difference in general user friendliness, i.e. without considering inventory type or company size, existed between kanban and the period review method. For both MRP and kanban the general operational performance was significantly higher compared to the reorder point and fixed order interval methods. Thus, the previous two methods were considered to be more user friendly, no matter inventory type were they are used or company size. 
Insert Tables 8 and 9 here

\subsection{Parameter Determination and Method Usage}

Table 10 shows a comparison between companies with perceived high and low performance of the respective method, measured in terms of user friendliness and operational performance. The two performance variables discussed in the methodology chapter and in the previous section were used. Respondents marking " 1 ", " 2 " or " 3 " on the 7-point scales were defined as "low performance"; and firms and respondents marking "5", “6” or "7" were defined as "high performance" firms. The modes of application defined in Table 2 were compared between the low and high performance firms using chi-square tests.

Insert Table 10 here

A few statistically significant differences between firms with low and high perceived planning performance were identified for the re-order point and MRP methods.

For the re-order point methods, the degree of analytical order point determination (i.e. calculating the order point as the sum of the demand during lead time plus safety stock rather than using experience) and the frequency of order point revision differed 
significantly between users with different perceived operational planning performance. Firms generating future demand data through MRP or monthly forecast calculations also showed significantly (at the $\mathrm{p}<0.10$ level) higher operational performance compared to those who used experience or simply the previous year's demand. Furthermore, many order changes before release were associated with significantly lower operational performance. The only significantly characteristic mode of application among re-order point users who find the methods user friendly is that they need to deal with fewer changes of planned orders before release.

For MRP users, analytical lead-time determination, frequency of safety stock revision, frequency of manufacturing lead-time revision and planning frequency differed most significantly between users with various degrees of perceived operational planning performance. MRP supported by an ERP system that generates re-planning suggestions is considered significantly more user friendly than systems without re-planning support in the ERP. Firms with higher frequencies of safety stock revision, purchasing lead-time revision and lower numbers of order changes before order release also found the method more user friendly compared to those that did not.

The findings confirm the expectations that analytical modes of determining parameters and higher review frequencies have positive impacts on planning performance. However, the relationships were only verified for some critical variables (determination and revision of order points for re-order point methods and lead-time determination and revision and safety stock revision for MRP) and not for the overall indexes, except for the review frequency index for the operational re-order point performance and user friendliness of MRP. The relationships were also only valid for the impact on the perceived operational 
performance of the methods and not for their perceived user friendliness. It can, though, be expected that the perceived user friendliness depends more on the user friendliness of available ERP systems than on the method used. The assumption about the planning frequency was verified for MRP regarding its impact on operational performance. The assumption about order modification was verified for both methods and performance measures, except for the operational performance of MRP. The assumption regarding automatic re-planning was verified for its impact on user friendliness but not for operational performance.

The reasons for high or low perceived planning performance among the fixed-order interval and run-out time planning users follow the same pattern as for MRP and re-order point users. Analytical determination of run-out time, order intervals and safety stocks seems to be important, as well as, frequent safety stock determination and few order changes before release. It is hard to draw and conclusions of the reasons for high or low kanban performance. One possible tendency is, though, that users that only need one kanban to start production show higher planning performance compared to those that need several kanbans. This verifies the need for small set-up times and batch sizes in order to successfully apply the kanban method. However, the findings related to the fixed-order interval, run-out time and kanban methods are not based on statistical significance tests but are rather visual analyses of the figures in Table 11.

Insert Table 11 here

http://mc.manuscriptcentral.com/tprs Email: ijpr@lboro.ac.uk 


\section{DISCUSSION}

The study showed that MRP is the most used and ROP the second most used method for controlling material flows to inventories in manufacturing companies. In distribution operations, however, ROP and ROP-related methods fixed order interval method, run-out time planning and kanban) are the most commonly used main methods. The findings do not verify the conclusions of Rabinovich and Evers (2002) that MRP related methods was also the most important method for controlling finished goods inventories, for example stocks in distribution operations.

MRP and kanban are perceived to result in better general performance compared to reorder point and fixed order interval methods. This is interesting as MRP is more dependent on the quality of the planning information and the ERP support than the other methods.

The most important application modes for achieving high operational planning performance among re-order point users were to determine the order point as the demand during the lead time plus a safety stock, and to frequently review this order point quantity. By doing so the method becomes more dynamic, i.e. responsive to demand and lead-time fluctuations. The method works best in a stable environment where the demand is smooth and lead times are short and fixed. However, several companies use the method in other environments and therefore require a more dynamic method in order to achieve a satisfactory planning performance. A corresponding indirect effect could be achieved by deriving the demand data from a requirements calculation or monthly forecasts instead of using the previous year's sales figures or an annual estimate. This performance impact was also identified in the study. It shows the importance of combining several methods in an 
integrated planning approach, and the possibility of using MRP as a complement to re-order point methods.

The study showed that accurate lead times and safety stocks are two of the most critical parameters for achieving high MRP performance. To achieve high accuracy, lead times must be periodically reviewed to reflect the current situation faithfully. This is an issue of balancing the cost of reviewing and the benefits of more accurate lead times. Manufacturing lead times could be calculated automatically from filed data in the ERP system or based on real-time logging of operation times. The same is true for safety stocks, which should be properly determined and frequently reviewed to allow for dynamic and efficient material planning. The identified importance of safety stock determination is interesting, because studies show that only a minority of companies use analytical safety stock approaches (e.g. Sandvig, 1998, Jonsson and Mattsson, 2006). Companies with a daily MRP planning frequency also showed significantly higher planning performance compared to those with weekly planning. The argument is the same as for more analytical determination and frequent revision, as it results in a more dynamic method. It is also in line with current practice. Jonsson and Mattsson (2006) showed that the majority of MRP users changed from weekly to daily planning frequencies between 1993 and 1999 and that daily planning now is the dominating planning frequency for all methods.

The findings further indicate that sufficient operational performance equates to a user friendly method. If the method results in high operational performance, for example as a result of analytically determined and frequently revised parameters, users are more likely to find the method user friendly. However, other issues affect the perceived user friendliness, for example, the characteristics of the ERP system that supports the planning process. For 
MRP, the user friendliness is also higher with an ERP system with automatic re-planning support, i.e. if the system is allowed to take more active control of the planning process.

The study shows that order quantity determination and revision have no impact at all on planning performance. Rather, the re-order point (or the replenishment level, run-out time, number of kanbans, respectively) is significantly the most important parameter to determine and review in re-order point methods and safety stock and lead times in MRP. This finding is interesting because order quantity related studies still receive greater emphasis in research.

Guiding managerial implications of the study are summarised in Table 11. Issues to consider and guidelines to follow are related to the three phases of designing and using material planning methods; 1) matching method and planning environment, 2) designing material planning method and 3) using material planning method.

\section{Insert Table 11 here}

\section{CONCLUSIONS}

The study concludes that the use of material planning methods differs depending on where along the material flow they are applied, whether the inventory is located in a manufacturing company or in distribution operations and between companies of various sizes. The modes of applying a material planning method affect its perceived performance. In particular, the way of determining and the review frequency of safety stocks and lead times have great importance for the planning performance of MRP methods, while the 
determination and review of order points, review frequencies and run-out times were important for re-order point methods.

The present study has focused on the operational strategies for determining and reviewing planning parameters and the planning frequencies of material planning methods. The conclusions clearly indicate the importance of how the material planning methods are applied, and in particular how the planning parameters are determined and reviewed, in order to successfully manage material planning.

In every planning and control situation there are different planning conditions that impact the possibility of favourable application modes, but which may also have a direct impact on planning performance. Such conditions include, for example, the method support in the ERP system, the educational and knowledge level of the material planning method, management commitment, the organisational design and functioning of planning and control, the available time for planning and control, the inventory accuracy and the leadtime precision in the ERP system. To further understand how to successfully employ material planning methods, it would thus be valuable to study the impact of planning conditions on operational strategies and their direct effect on planning performance.

There is a need for more focused studies on specific methods. Here, significant test could only be conducted for the MRP and re-order point methods. There is also a need for more focused studies on different planning environments in order to better understand the contextual impact on planning performance, for example, including the user environment (knowledge, management support, planning organisation, software support, lead time precision, etc.). A minority of the respondents represents distribution operations and the response rate was quite low for distributing companies. Most studies on material planning 
focuses on manufacturing operations. Therefore, it would be interesting with future studies focusing on material planning in distribution operations. In this study, subjective measures of the planning performance were used. Further development of instruments for measuring the direct and indirect planning performance are needed.

\section{REFERENCES}

Benton, W.C. 1991. Safety stock and service levels in periodic review systems, Journal of the Operations Research Society, 42, 1087-1095.

Berry, W. and Hill, T. 1992. Linking systems to strategy. International Journal of Operations and Production Management, 12 (10), 3-15.

Cerveny, R. and Scott, L. 1989. A survey of MRP implementation. Production and Inventory Management Journal, 30 (3), 31-35.

Enns, S. 1999. The effect of batch size selection on MRP performance. Computers \& Industrial Engineering, 37, 15-19.

Huang, S-T. 2000. Research on changes of total cost of dynamic economic lot size. Production Planning \& Control, 11 (1), 54-61.

Hair, J, Anderson, R, Tatham, R, Black, W. 1998. Multivariate data analysis, Prentice Hall, London.

Jonsson, P. and Mattsson, S-A. 2003. The implication of fit between planning environments and manufacturing planning and control methods. International Journal of Operations and Production Management, 23 (8), 872-900. 
Jonsson, P. and Mattsson, S-A. 2006. A longitudinal study of material planning applications in manufacturing companies. Forthcoming in the International Journal of Operations and Production Management.

Krajewski, L., King, B., Ritzman, L., Wong, D. 1987. Kanban, MRP and shaping the manufacturing environment, Management Science, 33 (1), 39-57.

Lee, H. 2002. Aligning supply chain strategies with product uncertainties. California Management Review, 44 (3), 105-119.

May, N. 1999. Managing safety stocks, Midrange ERP, October, 8.

Molinder, A. 1997. Joint optimization of lot-sizes, safety stocks and safety lead times in an MRP system. International Journal of Production Research, 35 (4), 983-994.

Newman, W., and Sridharan, V. 1992. Manufacturing planning and control: Is there one definite answer?. Production and Inventory Management Journal, 33 (1), 50-54.

Olhager, J. and Seldin, E. 2004. Supply chain management survey of Swedish manufacturing firms. International Journal of Production Economics, 89, 353-361.

Osteryoung, J, Nosari, E, McCarty, D, Reinhart, W,. 1986. Use of the EOQ model for inventory analysis. Production and Inventory Management Journal, 14 (3), 39-46.

Rabinovich, E. and Evers, P. 2002. Enterprise-wide adoption patterns of inventory management practices and information systems. Transportation Research Part E, 38, 389404.

Rabinovich, E., Dresner, M., Evers, P. 2003. Assessing the effects of operational processes and information systems on inventory performance. Journal of Operations Management, 21, 63-80. 
Reuter. V. 1978. The big gap in inventory management. International Journal of Purchasing and Materials Management, 14 (3), 227-230.

Safizadeh, H., Ritzman, L., Sharma, D., Wood, C. 1996. An empirical analysis of the product-process matrix. Management Science, 42 (11), 1576-1591.

Safizadeh, H. and Ritzman, L. 1997. Linking performance drivers in production planning and inventory control to process choice. Journal of Operations Management, 15, 389-403.

Sandvig, C. 1998. Simple solutions aren't the best ones. IIE Solutions, 30 (12), 28-29.

Seetharama, N., McLeavey, D., Billington, P. 1995. Production planning and inventory control. Prentice Hall, Englewood Cliffs.

Segerstedt, A. 2006. Master production scheduling and a comparison of materials requirements planning and cover-time planning. Forthcoming in the International Journal of Production Research.

Sheu, C., and Wacker, J.G. 2001. Effectiveness of planning and control systems: an empirical study of US and Japanese firms. International Journal of Production Research, $39(5), 887-905$.

Siegel, S., and Castellan, N.J. 1988. Nonparametric statistics for the behavioral sciences, McGraw-Hill.

Tang, O. and Grubbström, R. 2002. Planning and replanning the master production schedule under demand uncertainty. International Journal of Production Economics, 78, $323-334$.

Vollmann, T, Berry, W, Whybark, C, Jacobs, R. 2005. Manufacturing planning and control for supply chain management, McGraw Hill, New York. 
Wemmerlöv, U. and Whybark, D. 1984. Lot sizing under uncertainty in a rolling schedule environment. International Journal of Production Research, 22 (3), 467-484.

Whybark, C. and Williams, J. 1976. "Material requirements planning under uncertainty", Decision Sciences, 7 (4).

Wilkinson, S. 1996. Service level and safety stock based on probability, Control, April, 2325.

Zhao, X. and Lee, T. 1993. Freezing the master production schedule under demand uncertainty. Journal of Operations Management, 11, 185-205.

Zijm, W. and Buitenhek, R. 1996. Capacity planning and lead time management. International Journal of Production Economics, 46/47, 165-179. 


\section{TABLES}

Table 1 Characteristics of respondents

Table 2. Modes of application variables and measures

Table 3. Correlation between perceived planning performance and ITR/delivery service

Table 4. Number and percentages of method users

Table 5. Number and percentages of main method users

Table 6. Perceived user friendliness for the respective inventory management policy

Table 7. Perceived operational performance for the respective inventory management policy

Table 8. Number and percentages of method and main method users with different company sizes

Table 9. Perceived user friendliness and operational performance in general and in different company sizes

Table 10 Modes of application among companies with perceived low and high performance of main methods

Table 11. Managerial issues and guidelines related to planning phases 
Table 1. Characteristics of respondents

\begin{tabular}{|l|l|l|l|l|}
\hline & \multicolumn{2}{|c|}{$\begin{array}{c}\text { Manufacturing } \\
\text { companies }\end{array}$} & \multicolumn{2}{c|}{ Distribution operations } \\
\hline & $\begin{array}{l}\text { Number of } \\
\text { responses }\end{array}$ & Percentage & $\begin{array}{l}\text { Number of } \\
\text { responses }\end{array}$ & Percentage \\
\hline Size: & 45 & $30 \%$ & 22 & $45 \%$ \\
Small \& Medium sized & 103 & $70 \%$ & 27 & $55 \%$ \\
Large sized & $100 \%$ & & $100 \%$ \\
\hline
\end{tabular}

Note: Chi-square $3.44($ sign $\mathrm{p}<0.07)$

16

17

18

19

20

21

22

23

24

25

26

27

28

29

30

31

32

33

34

35

36

37

38

39

40

41

42

43

44

45

46

47

48

49

50

51

52

53

54

55

56

57

58

59

60

http://mc.manuscriptcentral.com/tprs Email: ijpr@lboro.ac.uk 
Table 2. Modes of application variables and measures

\begin{tabular}{|c|c|c|}
\hline Method & Variable & Measure \\
\hline \multirow{12}{*}{$\begin{array}{l}\text { Re-order } \\
\text { point } \\
\text { methods }\end{array}$} & $\begin{array}{l}\text { 1. Analytical order quantity } \\
\text { determination }\end{array}$ & $\begin{array}{l}\text { 1) Experience based fixed quantity or number of periods } \\
\text { covered; 2) Economic order quantity }\end{array}$ \\
\hline & $\begin{array}{l}\text { 2. Analytical safety stock } \\
\text { determination }\end{array}$ & $\begin{array}{l}\text { 1) Safety-stocks included in the re-order point or based on } \\
\text { judgment and experience, 2) Adding a percentage on the lead } \\
\text { time requirement or calculated from a specified service level }\end{array}$ \\
\hline & $\begin{array}{l}\text { 3. Analytical order } \\
\text { (replenishment }\end{array}$ & $\begin{array}{l}\text { 1) Based on experience and judgment, 2) Calculated as lead- } \\
\text { time demand plus safety stock }\end{array}$ \\
\hline & $\begin{array}{l}\text { 4. Ways of estimating } \\
\text { demand }\end{array}$ & 1) Experience or last year's demand, 2) forecasting or MRP \\
\hline & 5. Analytic determination & (Variable 1+Variable 2+Variable $3+$ Variable 4 )/4 $\rightarrow$ \\
\hline & index & $\begin{array}{l}\text { If } 1-1.25 \text { then code } 1 \text { (i.e. low overall analytical strategy); If } \\
1.75-2.00 \text { then code } 2 \text { (i.e. high overall analytical strategy). }\end{array}$ \\
\hline & $\begin{array}{l}\text { 6. Frequency of order } \\
\text { quantity revision }\end{array}$ & $\begin{array}{l}\text { 1) Annually or less frequent, 2) At least a couple of times per } \\
\text { year }\end{array}$ \\
\hline & $\begin{array}{l}\text { 7. Frequency of order point } \\
\text { revision }\end{array}$ & $\begin{array}{l}\text { 1) Annually or less frequent, 2) At least a couple of times per } \\
\text { year }\end{array}$ \\
\hline & 8. Review frequency index & $($ Variable $6+$ Variable 7$) / 2 \rightarrow$ \\
\hline & & $\begin{array}{l}\text { If } 1 \text { then code } 1 \text { (i.e. low overall frequency); If } 2 \text { then code } 2 \\
\text { (high overall frequency). }\end{array}$ \\
\hline & 9. Planning frequency & 1) Once a week or less frequent, 2) Daily or more frequent \\
\hline & $\begin{array}{l}\text { 10. Order changes before } \\
\text { release }\end{array}$ & 1) Very few, 2) A rather large amount \\
\hline \multirow{7}{*}{$\begin{array}{l}\text { Fixed order- } \\
\text { interval } \\
\text { method }\end{array}$} & $\begin{array}{l}\text { 1. Analytical determination of } \\
\text { the replenishment level }\end{array}$ & $\begin{array}{l}\text { 1) Based on experience and judgment, 2) Calculated as } \\
\text { demand during lead-time and review period plus safety stock }\end{array}$ \\
\hline & $\begin{array}{l}\text { 2. Analytical safety stock } \\
\text { determination }\end{array}$ & $\begin{array}{l}\text { 1) Safety-stocks included in the replenishment level or based } \\
\text { on judgment and experience, 2) Adding a percentage on the } \\
\text { lead time requirement or calculated from a specified service } \\
\text { level }\end{array}$ \\
\hline & $\begin{array}{l}\text { 3. Analytical determination of } \\
\text { review period }\end{array}$ & $\begin{array}{l}\text { 1) Based on experience and judgment, 2) calculated as the } \\
\text { economic order quantity }\end{array}$ \\
\hline & $\begin{array}{l}\text { 4. Analytical ways of } \\
\text { estimating demand }\end{array}$ & 1) Experience or last year's demand, 2) forecasting or MRP \\
\hline & $\begin{array}{l}\text { 5. Frequency of } \\
\text { replenishment level revision }\end{array}$ & $\begin{array}{l}\text { 1) Annually or less frequently, 2) At least a couple of times } \\
\text { per year }\end{array}$ \\
\hline & $\begin{array}{l}\text { 6. Frequency of review } \\
\text { period revision }\end{array}$ & $\begin{array}{l}\text { 1) Annually or less frequently, 2) At least a couple of times } \\
\text { per year }\end{array}$ \\
\hline & $\begin{array}{l}\text { 7. Order changes before } \\
\text { release }\end{array}$ & 1) Very few, 2) A rather large amount \\
\hline $\begin{array}{l}\text { Run-out time } \\
\text { planning }\end{array}$ & $\begin{array}{l}\text { 1. Analytical determination of } \\
\text { the run-out time }\end{array}$ & $\begin{array}{l}\text { 1) Available inventory divided by last years demand or } \\
\text { available inventory divided by forecasted demand, 2) } \\
\text { Available inventory divided by MRP generated future } \\
\text { demand or period by period calculation when the inventory }\end{array}$ \\
\hline
\end{tabular}


is zero.

1) Safety-stocks/safety time determined intuitively, 2) Adding a percentage on the lead time requirement or calculated from a specified service level

1) Experience based fixed quantity or number of periods covered, 2) Economic order quantity

1) No, 2) Yes, the run-out time in relation to the lead time

1) Annually or less frequent, 2) At least a couple of times per year

1) Annually or less frequent, 2) At least a couple of times per year

1) Once a week or less frequent, 2) Daily or more frequent

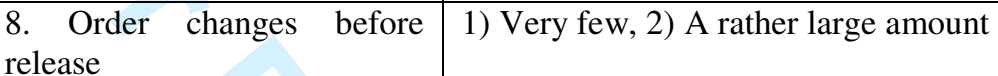

\begin{tabular}{l|l|l}
\hline Kanban & $\begin{array}{l}\text { 1. Electronic kanban type } \\
\text { (manufacturing) }\end{array}$ & $\begin{array}{l}\text { 1) One or two card kanban, 2) Electronic kanban (e-mail, } \\
\text { etc.) }\end{array}$
\end{tabular}
(manufacturing)

2. Analytical card 1) Based on judgment and experience, 2) Based on determination calculations

3. Electronic kanban type 1) Communication with carrier, mail or fax ${ }^{1}$, , 2) (suppliers)

$\begin{array}{ll}\text { 4. Number of cards to start } & \text { 1) For at least some items more than one card, 2) One card }\end{array}$ production

\begin{tabular}{l|l} 
5. Inventory account & 1) No item reservation, 2) Item reservation
\end{tabular}

1. Analytical order quantity 1) Experience based quantity or time period, 2) EOQ, determination

2. Analytical lead time determination dynamic optimization or lot-for-lot

1) Based on general judgment and experience, 2) Based on calculations in the ERP system or on monitored actual lead times

3. Analytical determination index

$($ Variable $1+$ Variable 2$) / 2 \rightarrow$

If 1 then code 1 (i.e. low overall analytical strategy); If 2 then code 2 (i.e. high overall analytical strategy).

4. Frequency of order 1) Annually or less frequent, 2) Reviews a couple of times a quantity revision $\quad$ year or more frequent

5. Frequency of safety stock 1) Annually or less frequent, 2) At least a couple of times per revision

6. Frequency of manufacturing lead time revision

1) Annually or less frequent, 2) Reviews a couple of times a year or more frequent

7. Frequency of purchasing lead time revision

8. Review frequency index

9. Planning frequency

1) Annually or less frequent, 2) Reviews a couple of times a year or more frequent

(Variable $4+$ Review $5+$ Review $6+$ Review 7) $/ 4 \rightarrow$

If $1-1.25$ the code 1 (i.e. low overall frequency); If 1.75-2.00 then code 2 (i.e. high overall frequency)

1) Once a week or less frequent; 2) Daily or more frequent

\footnotetext{
${ }^{1}$ No respondent used mail
} 
2

3

4

5

6

7

8

9

10

11

12

13

14

15

16

17

18

19

20

21

22

23

24

25

26

27

28

29

30

31

32

33

34

35

36

37

38

39

40

41

42

43

44

45

46

47

48

49

50

51

52

53

54

55

56

57

58

59

60

10. Order changes before release

11. Automatic re-planning
1) Very few; 2) A rather large amount

1) No re-planning support in the ERP system, 2) ERP system generates re-planning suggestions and/or conducts replanning

http://mc.manuscriptcentral.com/tprs Email: ijpr@lboro.ac.uk 
Table 3. Correlation between perceived planning performance and ITR/delivery service

\begin{tabular}{|l|l|l|}
\hline \multirow{2}{*}{ Perceived performance } & \multicolumn{2}{|c|}{ Objective performance } \\
\cline { 2 - 3 } & $\begin{array}{l}\text { Inventory turnover rate } \\
\text { (ITR) }\end{array}$ & Delivery service \\
\hline $\begin{array}{l}\text { User friendliness } \\
\text { Re-order point }\end{array}$ & $0.203^{*}$ & -0.040 \\
\hline $\begin{array}{l}\text { User friendliness } \\
\text { Fixed order interval }\end{array}$ & -0.061 & 0.246 \\
\hline $\begin{array}{l}\text { User friendliness } \\
\text { Run-out time planning }\end{array}$ & 0.060 & 0.080 \\
\hline $\begin{array}{l}\text { User friendliness } \\
\text { Kanban }\end{array}$ & -0.086 & 0.154 \\
\hline $\begin{array}{l}\text { User friendliness } \\
\text { MRP }\end{array}$ & 0.125 & $0.181^{*}$ \\
\hline $\begin{array}{l}\text { Operational } \\
\text { performance } \\
\text { Re-order point }\end{array}$ & $0.196^{*}$ & 0.020 \\
\hline $\begin{array}{l}\text { Operational } \\
\text { performance } \\
\text { Fixed order interval }\end{array}$ & 0.228 & -0.001 \\
\hline $\begin{array}{l}\text { Operational } \\
\text { performance } \\
\text { Run-out time planning }\end{array}$ & 0.169 & 0.169 \\
\hline $\begin{array}{l}\text { Operational } \\
\text { performance } \\
\text { Kanban }\end{array}$ & 0.073 & $0.242^{*}$ \\
\hline $\begin{array}{l}\text { Operational } \\
\text { performance } \\
\text { MRP }\end{array}$ & $0.324^{* *}$ & \\
\hline Ner Pearson & & $0.262^{* *}$ \\
\hline
\end{tabular}

Note: Pearson correlation, *Significant $(\mathrm{p}<0.05) ; * *$ Significant $(\mathrm{p}<0.01)$. 
Table 4. Number and percentages of method users

\begin{tabular}{|l|l|l|l|}
\hline \multirow{2}{*}{$\begin{array}{l}\text { Inventory } \\
\text { management policy }\end{array}$} & $\begin{array}{l}|c| \\
\text { Inventories of } \\
\text { purchased items }\end{array}$ & $\begin{array}{l}\text { Inventories of semi- } \\
\text { finished items }\end{array}$ & $\begin{array}{l}\text { Inventories in } \\
\text { distribution operations }\end{array}$ \\
\hline $\begin{array}{l}\text { Re-order point } \\
\text { method }\end{array}$ & $103(67 \%)$ & $55(36 \%)$ & $35(69 \%)$ \\
\hline $\begin{array}{l}\text { Fixed order interval } \\
\text { method }\end{array}$ & $13(8 \%)$ & $10(7 \%)$ & $13(25 \%)$ \\
\hline $\begin{array}{l}\text { Run-out time } \\
\text { planning }\end{array}$ & $23(15 \%)$ & $25(16 \%)$ & $12(24 \%)$ \\
\hline Kanban & $44(29 \%)$ & $36(23 \%)$ & $12(24 \%)$ \\
\hline MRP & $93(61 \%)$ & $96(63 \%)$ & $14(27 \%)$ \\
\hline Chi-square & $(\mathrm{p}<0.01)$ & & $(\mathrm{p}<0.01)$ \\
\hline
\end{tabular}

Note: Chi-square test indicated significantly $(\mathrm{p}<0.01)$ different use of inventory management policies within the respective inventory type. 
Table 5. Number and percentages of main method users

\begin{tabular}{|l|l|l|l|}
\hline \multirow{2}{*}{$\begin{array}{l}\text { Inventory } \\
\text { management policy }\end{array}$} & \multicolumn{3}{|c|}{ Inventory position } \\
\cline { 2 - 4 } & $\begin{array}{l}\text { Inventories of } \\
\text { purchased items }\end{array}$ & $\begin{array}{l}\text { Inventories of semi-finished } \\
\text { items }\end{array}$ & $\begin{array}{l}\text { Inventories in } \\
\text { distribution operations }\end{array}$ \\
\hline $\begin{array}{l}\text { Re-order point } \\
\text { method }\end{array}$ & $38(25 \%)$ & $29(19 \%)$ & $29(57 \%)$ \\
\hline $\begin{array}{l}\text { Fixed order interval } \\
\text { method }\end{array}$ & $6(4 \%)$ & $5(3 \%)$ & $10(20 \%)$ \\
\hline $\begin{array}{l}\text { Run-out time } \\
\text { planning }\end{array}$ & $9(6 \%)$ & $12(8 \%)$ & $11(22 \%)$ \\
\hline Kanban & $6(4 \%)$ & $14(9 \%)$ & $2(4 \%)$ \\
\hline MRP & $78(51 \%)$ & $82(54 \%)$ & $12(24 \%)$ \\
\hline Chi-square & $(\mathrm{p}<0.01)$ & $(\mathrm{p}<0.01)$ & $30.5(\mathrm{p}<0.01)$ \\
\hline
\end{tabular}

Note: Chi-square test indicated significantly $(\mathrm{p}<0.01)$ different use of inventory management policies within the respective inventory type. 
Table 6. Perceived user friendliness for the respective inventory management policy

\begin{tabular}{|l|l|l|l|}
\hline $\begin{array}{l}\text { Inventory } \\
\text { management } \\
\text { policy }\end{array}$ & $\begin{array}{l}|c| \\
\text { Inventories in manufacturing } \\
\text { operations }\end{array}$ & $\begin{array}{l}\text { Inventories in distribution } \\
\text { operations }\end{array}$ & F- statistics ${ }^{1}$ \\
\hline $\begin{array}{l}\text { Re-order point } \\
\text { method }\end{array}$ & $4.53(1.11)$ & $4.49(1.31)$ & 0.04 \\
\hline $\begin{array}{l}\text { Fixed order } \\
\text { interval method }\end{array}$ & $4.14(1.25)$ & $4.11(1.49)$ & 0.94 \\
\hline $\begin{array}{l}\text { Run-out time } \\
\text { planning }\end{array}$ & $4.73(1.24)$ & $4.13(1.88)$ & 0.11 \\
\hline Kanban & $5.05(1.41)$ & $4.50(2.22)$ & 0.30 \\
\hline MRP & $4.44(1.24)$ & $4.55(1.14)$ & 0.72 \\
\hline
\end{tabular}

Note: ${ }^{1}$ t tests between stocks in manufacturing operations and stocks in distribution operations. 
Table 7. Perceived operational performance for the respective inventory management policy

\begin{tabular}{|l|l|l|l|}
\hline \multirow{2}{*}{$\begin{array}{l}\text { Inventory } \\
\text { management } \\
\text { policy }\end{array}$} & $\begin{array}{l}|c| \\
\text { Inventories in manufacturing } \\
\text { operations }\end{array}$ & $\begin{array}{l}\text { Inventories in distribution } \\
\text { operations }\end{array}$ & F- statistics \\
\hline $\begin{array}{l}\text { Re-order point } \\
\text { method }\end{array}$ & $3.90(1.29)$ & $4.18(1.32)$ & 1.31 \\
\hline $\begin{array}{l}\text { Fixed order } \\
\text { interval method }\end{array}$ & $3.85(1.09)$ & $3.29(1.65)$ & 1.50 \\
\hline $\begin{array}{l}\text { Run-out time } \\
\text { planning }\end{array}$ & $4.67(1.21)$ & $4.29(1.44)$ & 0.09 \\
\hline Kanban & $4.84(1.22)$ & $4.40(1.71)$ & 1.01 \\
\hline MRP & $4.51(1.37)$ & $4.24(1.41)$ & 0.69 \\
\hline
\end{tabular}

Note: ${ }^{1} \mathrm{t}$ tests between stocks in manufacturing operations and stocks in distribution operations. 
Table 8. Number and percentages of method and main method users with different company sizes

\begin{tabular}{|c|c|c|c|}
\hline \multirow{2}{*}{$\begin{array}{l}\text { Inventory } \\
\text { management policy }\end{array}$} & \multicolumn{3}{|c|}{ Company size } \\
\hline & $\begin{array}{l}\text { Small and medium } \\
\#(\%)\end{array}$ & $\begin{array}{l}\text { Large } \\
\#(\%)\end{array}$ & Chi-square \\
\hline \multicolumn{4}{|l|}{ Method users: } \\
\hline $\begin{array}{l}\text { 1. Re-order point } \\
\text { method }\end{array}$ & $43(63 \%)$ & $85(65 \%)$ & 0.01 \\
\hline $\begin{array}{l}\text { 2. Fixed order interval } \\
\text { method }\end{array}$ & $13(19 \%)$ & $12(9 \%)$ & $3.61 *$ \\
\hline $\begin{array}{l}\text { 3. Run-out time } \\
\text { planning }\end{array}$ & $14(21 \%)$ & $33(25 \%)$ & 0.37 \\
\hline 4. Kanban & $22(32 \%)$ & $40(31 \%)$ & 0.06 \\
\hline 5. MRP & $40(59 \%)$ & $95(73 \%)$ & 1.15 \\
\hline \multicolumn{4}{|l|}{ Main method users: } \\
\hline $\begin{array}{l}\text { 1. Re-order point } \\
\text { method }\end{array}$ & $36(53 \%)$ & $46(35 \%)$ & $3.58^{*}$ \\
\hline $\begin{array}{l}\text { 2. Fixed order interval } \\
\text { method }\end{array}$ & $9(13 \%)$ & $17(13 \%)$ & 0.01 \\
\hline $\begin{array}{l}\text { 3. Run-out time } \\
\text { planning }\end{array}$ & $5(7 \%)$ & $13(10 \%)$ & 0.31 \\
\hline 4. Kanban & $5(7 \%)$ & $13(10 \%)$ & 0.31 \\
\hline 5. MRP & $32(47 \%)$ & $86(66 \%)$ & 2.50 \\
\hline
\end{tabular}

Note: No difference was significant on the $\mathrm{p}<0.05$ level. * indicates differences that are significant on the $\mathrm{p}<0.06$ level. 
Table 9. Perceived user friendliness and operational performance in general and in different company sizes

\begin{tabular}{|c|c|c|c|c|}
\hline \multirow[t]{2}{*}{$\begin{array}{l}\text { Inventory } \\
\text { management policy }\end{array}$} & \multicolumn{4}{|c|}{ Perceived user friendliness in different company sizes } \\
\hline & $\begin{array}{l}\text { Small and } \\
\text { medium }\end{array}$ & Large & F-statistics ${ }^{1}$ & $\begin{array}{l}\text { All } \\
\text { companies }\end{array}$ \\
\hline $\begin{array}{l}\text { 1. Re-order point } \\
\text { method }\end{array}$ & $4.55(1.16)$ & $4.48(1.81)$ & 0.10 & $4.52(1.16)$ \\
\hline $\begin{array}{l}\text { 2. Fixed order } \\
\text { interval method }\end{array}$ & $3.89(1.57)$ & $4.30(1.15)$ & 0.96 & $\begin{array}{l}4.12(1.35) \\
{[4]}\end{array}$ \\
\hline $\begin{array}{l}\text { 3. Run-out time } \\
\text { planning }\end{array}$ & $4.35(1.27)$ & $4.69(1.24)$ & 0.06 & $4.57(1.25)$ \\
\hline 4. Kanban & $5.00(1.64)$ & $4.94(1.49)$ & 0.03 & $\begin{array}{l}4.97(1.53) \\
{[2]}\end{array}$ \\
\hline 5. MRP & $4.43(1.34)$ & $4.48(1.20)$ & 0.06 & $4.46(1.22)$ \\
\hline \multirow[t]{3}{*}{ F-statistics ${ }^{2}$} & & & & $3.50^{* *}$ \\
\hline & \multicolumn{4}{|c|}{ Perceived operational performance in different company sizes } \\
\hline & $\begin{array}{l}\text { Small and } \\
\text { medium }\end{array}$ & Large & F-statistics ${ }^{1}$ & $\begin{array}{l}\text { All } \\
\text { companies }\end{array}$ \\
\hline $\begin{array}{l}\text { 1. Re-order point } \\
\text { method }\end{array}$ & $4.10(1.24)$ & $3.91(1.33)$ & 0.73 & $\begin{array}{l}3.97(1.30) \\
{[4,5]}\end{array}$ \\
\hline $\begin{array}{l}\text { 2. Fixed order } \\
\text { interval method }\end{array}$ & $3.50(1.67)$ & $3.67(1.16)$ & 0.13 & $\begin{array}{l}3.59(1.38) \\
{[4,5]}\end{array}$ \\
\hline $\begin{array}{l}\text { 3. Run-out time } \\
\text { planning }\end{array}$ & $4.28(1.23)$ & $4.43(1.36)$ & 0.16 & $4.38(1.30)$ \\
\hline 4. Kanban & $4.50(1.41)$ & $4.89(1.25)$ & 1.41 & $\begin{array}{l}4.78(1.30) \\
{[1,2]}\end{array}$ \\
\hline 5. MRP & $4.35(1.40)$ & $4.51(1.36)$ & 0.41 & $\begin{array}{l}4.47(1.37) \\
{[1,2]}\end{array}$ \\
\hline F-statistics ${ }^{2}$ & & & - & $7.55^{* *}$ \\
\hline & & & & \\
\hline
\end{tabular}

Note: ${ }^{1} \mathrm{t}$ tests between small/medium and large sized companies. ${ }^{2}$ ANOVA tests between different material planning methods, without considering company size. ${ }^{*}$ Significant on $\mathrm{p}<0.01$ level; $* *$ Significant on $\mathrm{p}<0.05$ level. 
Table 10 Modes of application among companies with perceived low and high performance of main methods

\begin{tabular}{|c|c|c|c|c|c|c|}
\hline \multirow{3}{*}{ Variable (Mode of application) } & \multicolumn{6}{|c|}{ Planning performance } \\
\hline & \multicolumn{3}{|c|}{ User friendliness } & \multicolumn{3}{|c|}{ Operational performance } \\
\hline & $\begin{array}{c}\text { Low } \\
\text { performance } \\
\text { Responses (\%) } \\
\end{array}$ & $\begin{array}{c}\text { High } \\
\text { performance } \\
\text { Responses (\%) } \\
\end{array}$ & Chi-square & $\begin{array}{c}\text { Low } \\
\text { performance } \\
\text { Responses (\%) } \\
\end{array}$ & $\begin{array}{c}\text { High } \\
\text { performance } \\
\text { Responses (\%) } \\
\end{array}$ & Chi-square \\
\hline \multicolumn{7}{|l|}{ Re-rder point method: } \\
\hline Analytical determination index & $11(69 \%)$ & $22(81 \%)$ & 1.37 & $19(53 \%)$ & $14(48 \%)$ & 0.13 \\
\hline Analytical order quantity determination & $18(82 \%)$ & $16(67 \%)$ & 0.98 & $14(52 \%)$ & $13(54 \%)$ & 0.03 \\
\hline Analytical safety stock determination & $20(77 \%)$ & $21(73 \%)$ & 0.15 & $13(45 \%)$ & $22(55 \%)$ & 0.70 \\
\hline Analytical order point determination & $10(62 \%)$ & $30(81 \%)$ & 2.08 & $2(13 \%)$ & $25(61 \%)$ & $9.98 * * *$ \\
\hline Demand from MRP or forecast & $12(63 \%)$ & $26(79 \%)$ & 1.50 & $7(32 \%)$ & $20(57 \%)$ & $3.50^{*}$ \\
\hline High review frequency index & $12(71 \%)$ & $23(82 \%)$ & 0.82 & $9(36 \%)$ & $23(66 \%)$ & $4.21 *$ \\
\hline High frequency of order quantity revision & $14(70 \%)$ & $21(78 \%)$ & 0.37 & $13(46 \%)$ & $21(55 \%)$ & 0.50 \\
\hline High frequency of order point revision & $14(67 \%)$ & $25(78 \%)$ & 0.86 & $7(29 \%)$ & $20(61 \%)$ & $5.51 * * *$ \\
\hline High planning frequency & $13(81 \%)$ & $20(69 \%)$ & 0.80 & $13(59 \%)$ & $19(46 \%)$ & 0.93 \\
\hline Many order changes before release & $26(84 \%)$ & $12(57 \%)$ & $4.54 * *$ & $25(61 \%)$ & $9(33 \%)$ & $4.98 * *$ \\
\hline \multicolumn{7}{|l|}{ Fixed order-interval system: } \\
\hline Analytical determination of replenishment level & $0($ of 2$)$ & $5(83 \%)$ & NA & $1(33 \%)$ & $2(43 \%)$ & NA \\
\hline Analytical safety stock determination & $1(50 \%)$ & $4(80 \%)$ & NA & $2(67 \%)$ & $2(100 \%)$ & NA \\
\hline Analytical determination of review period & 0 (of 2) & $3(50 \%)$ & NA & 0 (of 3$)$ & $2(67 \%)$ & NA \\
\hline Demand from MRP or forecast & $1(50 \%)$ & $6(100 \%)$ & NA & $2(67 \%)$ & $3(100 \%)$ & NA \\
\hline High frequency of replenishment lever revision & $1(50 \%)$ & $4(67 \%)$ & NA & $1(33 \%)$ & $3(100 \%)$ & NA \\
\hline High frequency of review period revision & $1(50 \%)$ & $5(83 \%)$ & NA & $1(33 \%)$ & $3(100 \%)$ & NA \\
\hline Many order changes before release & $1(50 \%)$ & $1(20 \%)$ & NA & $2(67 \%)$ & 0 (of 2) & NA \\
\hline \multicolumn{7}{|l|}{ Run-out time planning: } \\
\hline Analytical determination of the run-out time & $1(50 \%)$ & $2(20 \%)$ & NA & $1(25 \%)$ & $8(77 \%)$ & NA \\
\hline Analytical safety stock determination & $0($ of 5$)$ & $2(15 \%)$ & NA & $1(25 \%)$ & $4(50 \%)$ & NA \\
\hline Analytical order quantity determination & $2(100 \%)$ & $0($ of 10$)$ & NA & $1(20 \%)$ & $1(11 \%)$ & NA \\
\hline Use of priority numbers & $0($ of 2$)$ & $3(30 \%)$ & NA & $1(25 \%)$ & $1(11 \%)$ & NA \\
\hline High frequency of safety stock revision & $1(100 \%)$ & $7(70 \%)$ & NA & $2(50 \%)$ & $7(85 \%)$ & NA \\
\hline High frequency of order quantity revision & $1(50 \%)$ & $5(50 \%)$ & NA & $1(20 \%)$ & $5(57 \%)$ & NA \\
\hline High planning frequency & $2(100 \%)$ & $4(60 \%)$ & NA & $2(50 \%)$ & $4(46 \%)$ & NA \\
\hline Many order changes before release & $1(50 \%)$ & $3(30 \%)$ & NA & $3(60 \%)$ & $2(22 \%)$ & NA \\
\hline \multicolumn{7}{|l|}{ MRP: } \\
\hline Analytical determination index & $13(72 \%)$ & $24(86 \%)$ & 1.27 & $11(65 \%)$ & $29(81 \%)$ & 1.57 \\
\hline Analytical order quantity determination & $25(73 \%)$ & $31(82 \%)$ & 0.67 & $26(72 \%)$ & $36(73 \%)$ & 0.02 \\
\hline Analytical lead time determination & $20(71 \%)$ & $36(80 \%)$ & 0.71 & $18(62 \%)$ & $44(81 \%)$ & $3.76 * *$ \\
\hline High review frequency index & $20(62 \%)$ & $24(92 \%)$ & $6.96 * * *$ & $23(64 \%)$ & $22(71 \%)$ & 1.63 \\
\hline High frequency of order quantity revision & $20(69 \%)$ & $35(81 \%)$ & 1.48 & $24(73 \%)$ & $37(71 \%)$ & 0.02 \\
\hline High frequency of safety stock revision & $22(65 \%)$ & $33(89 \%)$ & $6.08 * *$ & $26(65 \%)$ & $35(83 \%)$ & $3.62 * *$ \\
\hline High frequency of manuf. lead time revision & $34(71 \%)$ & $24(88 \%)$ & 2.46 & $38(65 \%)$ & $24(96 \%)$ & $8.59 * * *$ \\
\hline High frequency of purchasing lead time revision & $29(67 \%)$ & $25(89 \%)$ & $4.44 * *$ & $37(71 \%)$ & $24(75 \%)$ & 0.15 \\
\hline High planning frequency & $13(72 \%)$ & $43(78 \%)$ & 0.27 & $13(56 \%)$ & $49(79 \%)$ & $4.31 * *$ \\
\hline Many order changes before release & $39(91 \%)$ & $15(56 \%)$ & $11.46 * * *$ & $39(80 \%)$ & $23(64 \%)$ & 2.59 \\
\hline Automatic replanning & $11(57 \%)$ & $46(84 \%)$ & $5.29 * *$ & $15(83 \%)$ & $48(72 \%)$ & 1.01 \\
\hline \multicolumn{7}{|l|}{ Kanban: } \\
\hline Electronic kanban type (manufacturing) & $1(33 \%)$ & $3(38 \%)$ & NA & $1(50 \%)$ & $3(33 \%)$ & NA \\
\hline Analytical card determination & $2(33 \%)$ & $8(89 \%)$ & NA & $2(100 \%)$ & $7(88 \%)$ & NA \\
\hline Electronic kanban type (suppliers) & $1(33 \%)$ & $3(60 \%)$ & NA & $1(50 \%)$ & $2(50 \%)$ & NA \\
\hline Only one card to start production & 0 (of 1$)$ & $4(57 \%)$ & NA & 0 (of 1$)$ & $3(43 \%)$ & NA \\
\hline Item reservation conducted & $2(67 \%)$ & $6(100 \%)$ & NA & $1(50 \%)$ & $5(100 \%)$ & NA \\
\hline
\end{tabular}

Note: A "low performance" firm has a perceived degree of performance of "5", "6" or "7", while a "low performance" firm has a perceived degree of performance of "1", "2" or " 3 ", Figures in the table illustrate the number (and percentage of total) of respondents with answer alternative 2 in table 2, i.e. the alternatives defined as the analytical strategy and high frequency. * Statistically significant at the $\mathrm{p}<0.10$ level; ** Statistically significant at the $\mathrm{p}<0.05$ level; $* * *$ Statistically significant at the $\mathrm{p}<0.01$ level 
Table 11. Managerial issues and guidelines related to planning phases

\begin{tabular}{|c|c|c|}
\hline Phase & Issue & Guideline \\
\hline $\begin{array}{l}\text { 1. Matching method and } \\
\text { planning environment }\end{array}$ & Inventory types & $\begin{array}{l}\text { - Re-order point methods are } \\
\text { appropriate methods for control of } \\
\text { material flows in distribution } \\
\text { operations inventories (finished } \\
\text { products and spare parts). } \\
\text { - MRP is the main method for } \\
\text { controlling inventories of } \\
\text { manufactured semi-finished items } \\
\text { with dependent demand and for } \\
\text { purchased items but re-order point } \\
\text { and especially kanban methods } \\
\text { could perform well if used for items } \\
\text { with appropriate characteristics. } \\
\text { MRP and kanban have higher } \\
\text { general planning performance for } \\
\text { controlling inventories of semi- } \\
\text { finished goods compared to re- } \\
\text { order point and fixed order interval } \\
\text { methods. }\end{array}$ \\
\hline $\begin{array}{l}\text { 2. Designing material } \\
\text { planning methods }\end{array}$ & $\begin{array}{l}\text { Critical } \\
\text { parameters }\end{array}$ & $\begin{array}{l}\text { - For re-order point methods the } \\
\text { determination of re-order points and } \\
\text { safety stocks are critical for } \\
\text { achieving high perceived planning } \\
\text { performance } \\
\text { - For MRP the determination of lead } \\
\text { times and safety stocks are critical } \\
\text { for achieving high perceived } \\
\text { planning performance }\end{array}$ \\
\hline $\begin{array}{l}\text { 3. Using material planning } \\
\text { methods }\end{array}$ & $\begin{array}{l}\text { Critical } \\
\text { strategies }\end{array}$ & $\begin{array}{l}\text { - High review frequency of the } \\
\text { critical parameters is important for } \\
\text { achieving high perceived planning } \\
\text { performance. } \\
\text { - For MRP high planning frequency } \\
\text { is also important for achieving high } \\
\text { perceived planning performance. } \\
\text { - It is important to fine tune the } \\
\text { planning system so that only a } \\
\text { minority of the order suggestions } \\
\text { need to be modified before release } \\
\text { and that no "unnecessary" } \\
\text { modification is done. }\end{array}$ \\
\hline
\end{tabular}


1

2

3

4

5

6

7

8

9

10

11

12

13

14

15

16

17

18

19

20

21

22

23

24

25

26

27

28

29

30

31

32

33

34

35

36

37

38

39

40

41

42

43

44

45

46

47

48

49

50

51

52

53

54

55

56

57

58

59

60

\section{FIGURES}

Figure 1. The proposed relationships between inventory types, manufacturing planning environment, planning parameters, planning frequency and planning performance. 


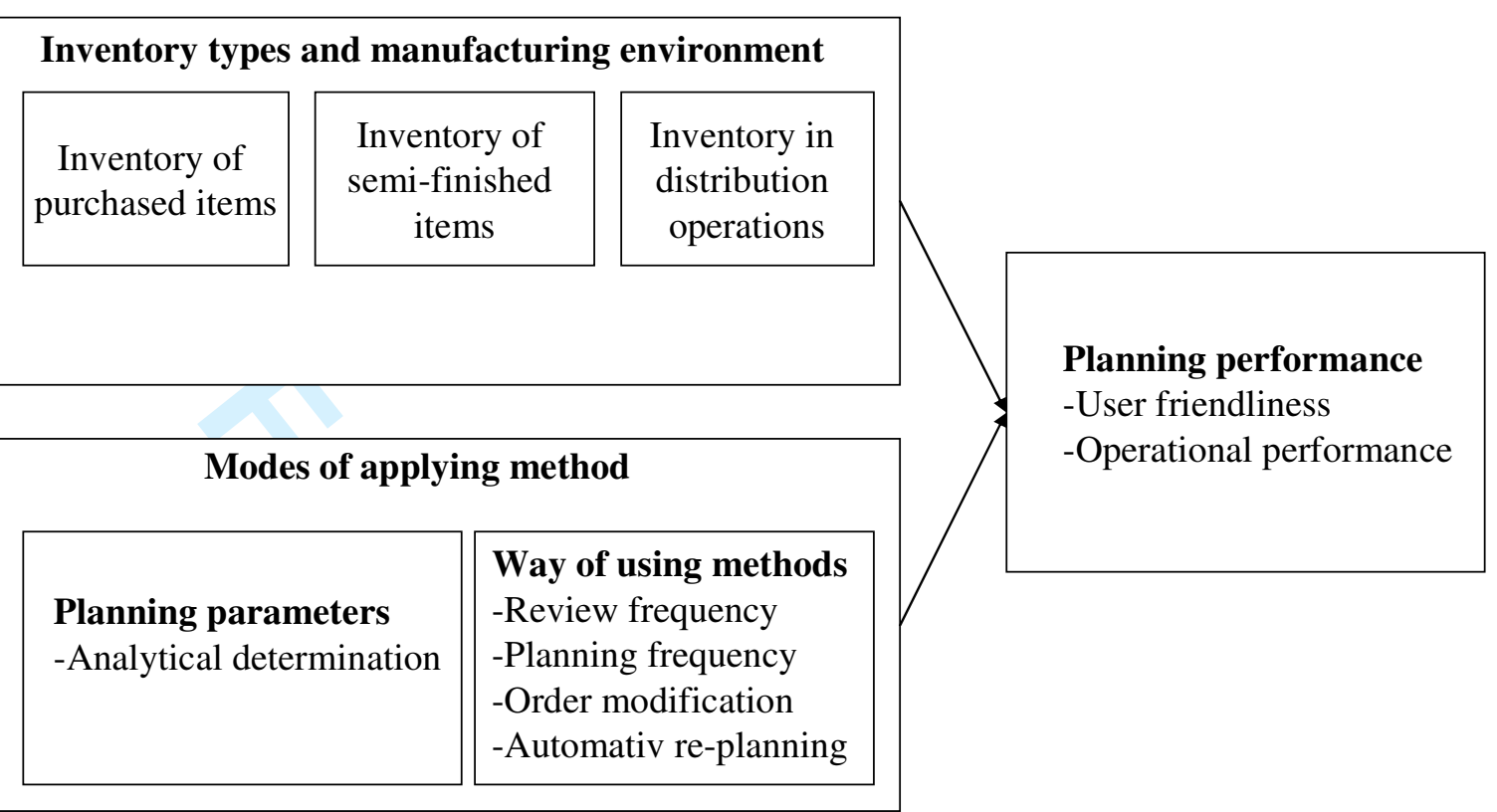

Figure 1. The proposed relationships between inventory types, manufacturing planning environment, planning parameters, planning frequency and planning performance. 